University of Wollongong

Research Online

Faculty of Engineering - Papers (Archive)

Faculty of Engineering and Information

Sciences

$1-1-2012$

\title{
Facile synthesis of graphene-molybdenum dioxide and its lithium storage properties
}

Kuok Hau Seng

University of Wollongong, kseng@uow.edu.au

Guo Dong Du

University of Western Sydney, gd616@uow.edu.au

$\mathrm{Li} \mathrm{Li}$

University of Wollongong, li@uow.edu.au

Zhixin Chen

University of Wollongong, zchen@uow.edu.au

Hua-Kun Liu

University of Wollongong, hua@uow.edu.au

See next page for additional authors

Follow this and additional works at: https://ro.uow.edu.au/engpapers

Part of the Engineering Commons

https://ro.uow.edu.au/engpapers/5219

\section{Recommended Citation}

Seng, Kuok Hau; Du, Guo Dong; Li, Li; Chen, Zhixin; Liu, Hua-Kun; and Guo, Zaiping: Facile synthesis of graphene-molybdenum dioxide and its lithium storage properties 2012, 16072-16077.

https://ro.uow.edu.au/engpapers/5219

Research Online is the open access institutional repository for the University of Wollongong. For further information contact the UOW Library: research-pubs@uow.edu.au 
Authors

Kuok Hau Seng, Guo Dong Du, Li Li, Zhixin Chen, Hua-Kun Liu, and Zaiping Guo 


\title{
Journal of

\section{Facile synthesis of graphene-molybdenum dioxide and its lithium storage properties $\dagger$}

\author{
Kuok Hau Seng, ${ }^{a b}$ Guo Dong Du, ${ }^{c} \mathrm{Li} \mathrm{Li},{ }^{a}$ Zhi Xin Chen, ${ }^{b}$ Hua Kun Liu ${ }^{a}$ and Zai Ping Guo*ab \\ Received 5th May 2012, Accepted 21st June 2012 \\ DOI: $10.1039 / \mathrm{c} 2 \mathrm{jm} 32822 \mathrm{~d}$
}

\begin{abstract}
Graphene-molybdenum dioxide composites in several ratios have been prepared through a facile synthesis method. Depending on the ratio, the as synthesized composites have either 2-dimensional graphene sheets with $\mathrm{MoO}_{2}$ particles anchored to them or a clustered agglomerate morphology. The composites have been characterised using Raman spectroscopy, X-ray diffraction, and electron diffraction to confirm the monoclinic $\mathrm{MoO}_{2}$ phase that is present. Lithium storage properties of the assynthesised samples were tested in a coin-type half cell assembly to determine the relationship between the ratio and the electrochemical performance. The sample with highest amount of $\mathrm{MoO}_{2}(78 \mathrm{wt} \%)$ displayed the most promising lithium storage properties, with stable cycling performance at $0.2 \mathrm{~A} \mathrm{~g}^{-1}$ that shows negligible capacity loss over 50 cycles, retaining a capacity of $640 \mathrm{~mA} \mathrm{~h} \mathrm{~g}{ }^{-1}$. The rate capabilities were also tested, and show a capacity of $380 \mathrm{~mA} \mathrm{~h} \mathrm{~g}^{-1}$ at $2.0 \mathrm{~A} \mathrm{~g}^{-1}$, which is comparable to the theoretical capacity of graphite and previously reported work on similar materials.
\end{abstract}

\section{Introduction}

Electrochemical energy storage has become an increasingly important area of research in recent years. This is due to the increasing demand for portable electronic devices that are powered by batteries. In addition, electric vehicles and power grid storage have also become emerging markets for electrochemical energy storage systems. ${ }^{1,2}$ Among all of these, lithium-ion batteries (LIBs) are the most promising systems due to their high power and energy density. ${ }^{3}$ Further improvement is required, however, to fulfil the demands for high energy storage capacity.

One of the methods to improve the energy density of LIBs is to find alternative active materials. The anode of conventional LIBs is based on graphite, which has a theoretical capacity of $372 \mathrm{~mA}$ $\mathrm{h} \mathrm{g}^{-1}$. Much research has been conducted on using alternative materials such as graphene, ${ }^{4-7}$ metals,,${ }^{8-14}$ and metal oxides. ${ }^{15-19}$ Graphene has the advantages of high electrical conductivity and high theoretical capacity compared to graphite. ${ }^{20-22}$ On the other hand, metals and metal oxides have higher gravimetric and volumetric capacity compared to carbon materials. They suffer, however, from large volume changes during lithium reactions. As

anstitute for Superconducting and Electronic Materials, University of Wollongong, NSW 2522, Australia. E-mail: zguo@uow.edu.au; Web: http://isem.uow.edu.au; Fax: +61 24221 5731; Tel: +612 42215225

${ }^{b}$ School of Mechanical, Materials and Mechatronic Engineering, University of Wollongong, NSW 2522, Australia

'Solar Energy Technologies, The School of Computing, Engineering and Mathematics, University of Western Sydney, Locked Bag 1797, Penrith, NSW 2751, Australia

$\dagger$ Electronic supplementary information (ESI) available: SEM and TEM images of pure- $\mathrm{MoO}_{2}$ and pure-graphene; EDS mapping of GM31; voltage profiles and CV of all samples. See DOI: 10.1039/c2jm32822d a result, many researchers are turning to composites of graphene-metal ${ }^{23-25}$ and graphene-metal oxides ${ }^{26-31}$ to improve the performance of anode materials.

Molybdenum dioxide $\left(\mathrm{MoO}_{2}\right)$ is a good candidate anode material due to its low electrical resistivity $\left(8.8 \times 10^{-5} \Omega \mathrm{cm}\right)$ and high theoretical capacity $\left(838 \mathrm{~mA} \mathrm{~h} \mathrm{~g}^{-1}\right) .{ }^{32-39}$ Although $\mathrm{MoO}_{2}$ in different morphologies has been previously studied, the longterm cycling stability during lithium storage could be further improved. This has led to studies on carbon- $\mathrm{MoO}_{2}$ composites, which showed improved cycling stability. ${ }^{40-45}$ Carbon coating, however, may not be an effective strategy to improve the cycling stability and volume expansion of the active material. This is because carbon coating on the surface of the active material may not effectively release the stress during volume expansion and thus may possibly slow down the kinetics of the lithium-ions reaching the inner parts of the material. Furthermore, the carbon coating layer may crack and pulverise, which then leads to formation of dead volume in the electrode. Graphene is a flexible 2-dimensional sheet with electron clouds on both surfaces. It is an excellent candidate to provide good electronic conductivity and, at the same time, buffer the volume expansion of the $\mathrm{MoO}_{2}$. Recently, Sun et al. reported on a hierarchical graphene- $\mathrm{MoO}_{2}$ structure which shows good cycling performance for up to 70 cycles. ${ }^{46}$ In this work, we report the facile synthesis of a graphene- $\mathrm{MoO}_{2}$ composite, where two distinct morphologies were obtained. Our synthesis method comprises a simple solution mixing of precursors and subsequent thermal reduction, in which samples were prepared in gram-scale quantities. Through adjusting the ratio of precursors, a nanostructured graphene$\mathrm{MoO}_{2}$ composite with two different morphologies was synthesised, namely a clustered agglomerate and 2-dimensional 
nanosheets anchored with $\mathrm{MoO}_{2}$ nanoparticles. In addition, to the best of our knowledge, this is the first work investigating the relationship between the graphene- $\mathrm{MoO}_{2}$ ratio and the lithium storage performance.

\section{Experimental methods}

\subsection{Synthesis of graphene oxide}

Graphene oxide was prepared using a procedure similar to that described in our previous works..$^{23,26,47}$ In brief, $10 \mathrm{~g}$ of natural graphite (Sigma Aldrich), $5 \mathrm{~g}$ of $\mathrm{K}_{2} \mathrm{~S}_{2} \mathrm{O}_{8}$ (Sigma Aldrich), and $5 \mathrm{~g}$ of $\mathrm{P}_{2} \mathrm{O}_{5}$ (Sigma Aldrich) were added to $30 \mathrm{ml}$ concentrated $\mathrm{H}_{2} \mathrm{SO}_{4}$ (Sigma Aldrich). The solution was heated to $80{ }^{\circ} \mathrm{C}$ and thermally isolated for 6 hours. The solution was then carefully diluted with de-ionised water, vacuum filtered, and washed until the rinse water $\mathrm{pH}$ became neutral. The filtrate was dried under vacuum at $40{ }^{\circ} \mathrm{C}$ overnight. The pre-oxidised graphite was then oxidised using the Hummers method. $2 \mathrm{~g}$ of pre-oxidised graphite and $1 \mathrm{~g}$ of $\mathrm{NaNO}_{3}$ (Sigma Aldrich) were added to $46 \mathrm{ml} \mathrm{H}_{2} \mathrm{SO}_{4}$ cooled to $0{ }^{\circ} \mathrm{C}$ in an ice bath. $6 \mathrm{~g}$ of $\mathrm{KMnO}_{4}$ (Sigma Aldrich) was gradually added to the solution with vigorous stirring. The temperature was carefully monitored to not exceed $20^{\circ} \mathrm{C}$. The mixture was removed from the ice bath and heated at $35^{\circ} \mathrm{C}$ for 2 hours. After that, $92 \mathrm{ml}$ of de-ionised water was slowly added to the mixture. After 15 minutes, $140 \mathrm{ml}$ of warm water was added in to terminate the reaction. $30 \%$ hydrogen peroxide was added dropwise until the solution turned bright yellow and the bubbling stopped. The mixture was then centrifuged and washed with warm water until the $\mathrm{pH}$ of the upper layer was neutral. Then, graphite oxide was re-dispersed in water and ultrasonicated at $40 \%$ amplitude for 2 hours. Finally, a dark brown solution was obtained and was centrifuged at $3000 \mathrm{rpm}$ to remove un-exfoliated graphite oxide. The graphene oxide solution obtained was at a concentration of $5 \mathrm{mg} \mathrm{ml}^{-1}$.

\subsection{Synthesis of graphene- $\mathrm{MoO}_{2}$}

Graphene- $\mathrm{MoO}_{2}$ composites were synthesized by a simple mixing and reduction process, as described in Fig. 1. A calculated amount of phosphomolybdic acid hydrate (PMA, Sigma Aldrich) was added to the $5 \mathrm{mg} \mathrm{ml}^{-1}$ graphene oxide (GO) solution, which was sonicated for 30 minutes and left to dry in a Petri dish at $40{ }^{\circ} \mathrm{C}$ overnight. The resultant waxy solid was collected, placed on a quartz boat, and then heated in a tube furnace at $500{ }^{\circ} \mathrm{C}$ for 2 hours under $200 \mathrm{ml} \mathrm{min}^{-1}$ flow of $10 \% \mathrm{H}_{2}$ in argon. A total of three samples with different ratios of graphene oxide to phosphomolybdic acid were synthesized, namely, GM13 (1 g GO and 3 g PMA), GM11 (1 g GO and 1 g PMA),

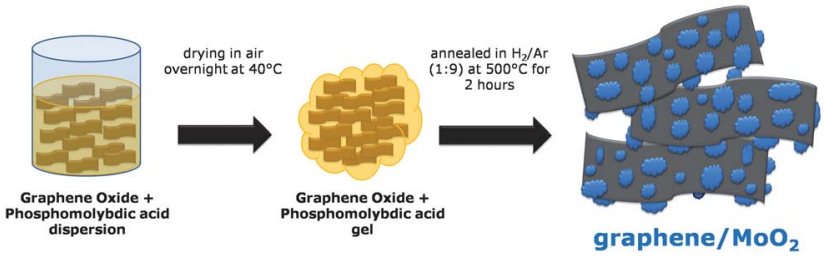

Fig. 1 Schematic representation of the synthesis procedure for graphene- $\mathrm{MoO}_{2}$ composite. and GM31 (3 g GO and $1 \mathrm{~g}$ PMA). In each synthesis the amounts of samples that were collected are about $1.7 \mathrm{~g}$ for GM13 and GM31, and about $0.85 \mathrm{~g}$ for GM11. The syntheses have been repeated at least twice. Graphene and $\mathrm{MoO}_{2}$ samples were prepared using the same method for comparison, and they are herein denoted as "pure-graphene" and "pure- $\mathrm{MoO}_{2}$ ".

\subsection{Characterisation}

Electrochemical characterisation of the samples was conducted in 2032-type coin cells. The samples were firstly mixed thoroughly with acetylene black and polyvinylidene difluoride in an $8: 1: 1$ ratio, respectively. $N$-Methyl-2-pyrrolidone was added dropwise to the mixture to form a uniform slurry, which was then coated onto $1 \mathrm{~cm}^{2}$ pieces of copper foil. Then, the resultant electrodes were left to dry overnight in a vacuum oven at $80{ }^{\circ} \mathrm{C}$. The electrodes were then pressed under approximately $200 \mathrm{~kg}$ $\mathrm{cm}^{-2}$ pressure before being assembled in an argon filled glove box. Lithium foil was used as a counter-electrode, Celgard polypropylene membranes were used as separators, and $1 \mathrm{M}$ $\mathrm{LiPF}_{6}$ in ethylene carbonate and diethyl carbonate $(1: 1 \mathrm{v} / \mathrm{v})$ was used as the electrolyte. All the cells were tested in the voltage window of 0.01 to $3.0 \mathrm{~V}$ ( $v s$. $\mathrm{Li} / \mathrm{Li}^{+}$). The scan rate used for the cyclic voltammetry $(\mathrm{CV})$ test is $0.1 \mathrm{mV} \mathrm{s}^{-1}$.

Galvanostatic charge-discharge tests were performed on a Land Battery Tester, and CV was performed on a CHI 660 electrochemistry workstation. X-ray diffraction (XRD) of the samples was performed on a GBC MMA facility; transmission electron microscopy (TEM) of the samples was performed on a JEOL 2011 instrument; scanning electron microscopy (SEM) was performed on a JEOL 7500; thermo-gravimetric analysis (TGA) was performed on a Mettler Toledo TGA; and Raman spectroscopy was performed on a JY HR 800 spectrometer with a $632.81 \mathrm{~nm}$ HeNe laser.

\section{Results and discussion}

TGA analysis was performed on all the samples to determine the actual weight ratios. All samples were heated in air at a rate of

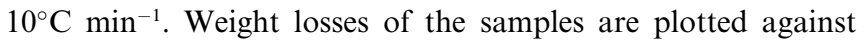
temperature in Fig. 2(a), and the weight ratios from TGA are tabulated in Table S1.† GM13, GM11 and GM31 contained $22 \mathrm{wt} \%, 40 \mathrm{wt} \%$ and $64 \mathrm{wt} \%$ of graphene respectively. For the pure- $\mathrm{MoO}_{2}$ sample, a $10 \%$ weight increase was observed starting from $300{ }^{\circ} \mathrm{C}$, where $\mathrm{MoO}_{2}$ is oxidised to $\mathrm{MoO}_{3}$. A slight weight loss was recorded below $120^{\circ} \mathrm{C}$ for the pure-graphene sample, which can be attributed to the loss of absorbed moisture. The decomposition of graphene in air started at $500{ }^{\circ} \mathrm{C}$, where a sharp drop in weight can be observed. As for the composite samples, similar patterns were observed, with a slight weight loss occurring at low temperature $\left(<120^{\circ} \mathrm{C}\right)$, followed by decomposition of the graphene $\left(>400{ }^{\circ} \mathrm{C}\right)$ and a plateau after $600{ }^{\circ} \mathrm{C}$. In addition, the weight increase indicative of the oxidation of $\mathrm{MoO}_{2}$ to $\mathrm{MoO}_{3}$ was not observed from the TGA plots for the graphene- $\mathrm{MoO}_{2}$ composite samples. The black powder that we have initially put into the platinum crucible turned white at the end of the analysis. This is an indication that $\mathrm{MoO}_{2}$ (pure- $\mathrm{MoO}_{2}$ is dark blue in colour) was oxidized and the weight remaining after $600{ }^{\circ} \mathrm{C}$ is indicative of $\mathrm{MoO}_{3}$. The white powders were also tested on the 

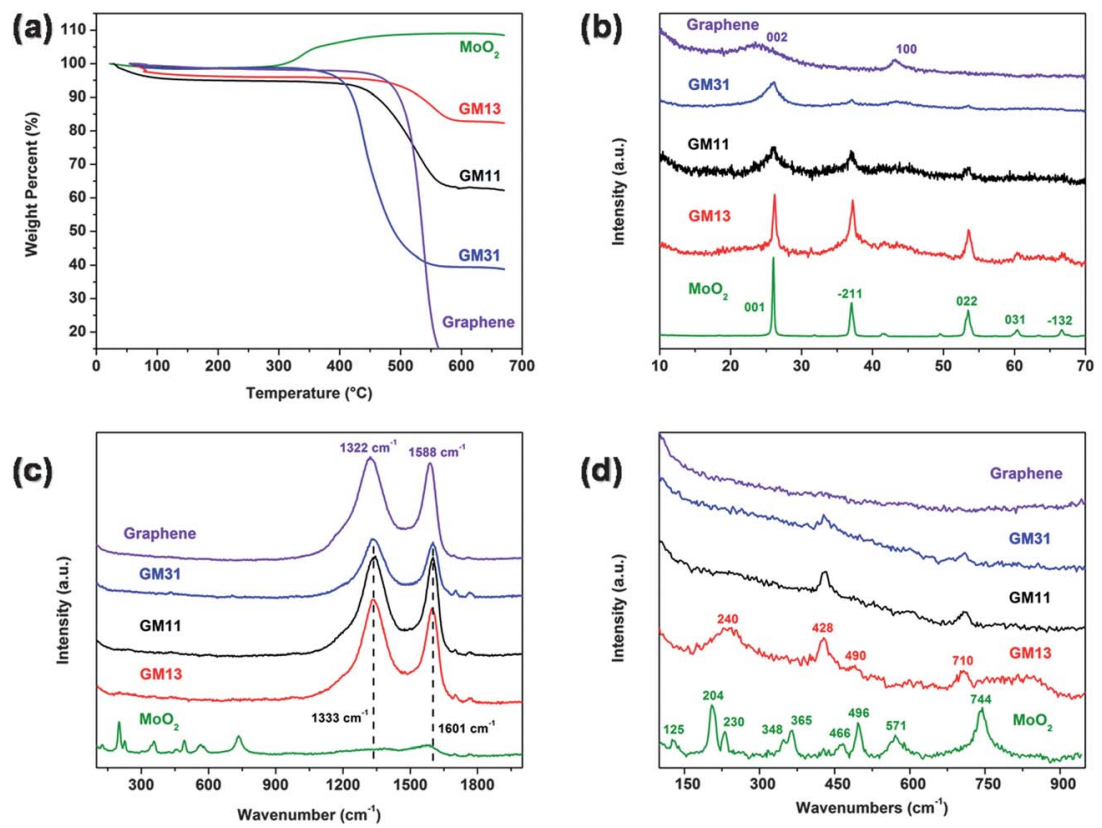

Fig. 2 (a) Thermogravimetric analysis of the samples in air with a heating rate of $10^{\circ} \mathrm{C}$ per minute; (b) X-ray diffraction patterns of all the samples; (c) Raman spectra from $100 \mathrm{~cm}^{-1}$ to $2000 \mathrm{~cm}^{-1}$; and (d) Raman spectra from $100 \mathrm{~cm}^{-1}$ to $1000 \mathrm{~cm}^{-1}$ with minimal laser exposure time.

XRD to confirm the $\mathrm{MoO}_{3}$ phase. A possible explanation is the masking of weight increase due to oxidation of $\mathrm{MoO}_{2}$ to $\mathrm{MoO}_{3}$ by the weight loss of graphene decomposition at the same temperature region. It should be noted, however, that increasing the amount of $\mathrm{MoO}_{2}$ in the sample lowers the decomposition temperature of the graphene. This might be due to the catalytic effect of molybdenum oxides during the decomposition process. Similar results have been reported previously for metal oxidegraphene and metal oxide-carbon composites. ${ }^{48-50}$ Nevertheless, further investigation is required to verify this phenomenon.

$\mathrm{X}$-ray diffraction was performed to identify the composition of the samples, and the diffraction patterns are plotted in Fig. 2(b). The pure- $\mathrm{MoO}_{2}$ sample shows sharp peaks that match monoclinic phase $\mathrm{MoO}_{2}$ (ICDD 32-0671), which belongs to the $P 21 / n$ (no. 14) space group. It should be noted that as the ratio of graphene increases, the $\mathrm{MoO}_{2}$ peaks appear more broadened and the intensity decreases. This is an indication of a decrease in the crystallite size of $\mathrm{MoO}_{2}$. In addition, a much broadened (001) reflection of $\mathrm{MoO}_{2}$ is observed in the diffraction pattern of GM31. This can be associated with the lower crystallinity, and larger amount of graphene ( $>50 \mathrm{wt} \%)$ in the samples. Inspection of the diffraction pattern of the pure-graphene sample shows broad humps, which can be indexed to the (002) and (100) reflections of graphite.

To further investigate the composition, the samples were characterised by Raman spectroscopy. The spectrum of the pure$\mathrm{MoO}_{2}$ sample in Fig. 2(c) shows several peaks which are characteristic of $\mathrm{MoO}_{2} \cdot{ }^{51}$ The spectrum of the graphene sample shows two major peaks at $1322 \mathrm{~cm}^{-1}$ and $1590 \mathrm{~cm}^{-1}$, which represent the $\mathrm{D}$ and $\mathrm{G}$ bands, respectively. ${ }^{7,23}$ On the other hand, spectra of the composite samples show slight shifts towards higher wave numbers. The $\mathrm{D}$ and $\mathrm{G}$ band maxima are at 1336 $\mathrm{cm}^{-1}$ and $1601 \mathrm{~cm}^{-1}$ respectively. In addition, the peaks associated with $\mathrm{MoO}_{2}$ were not observed in the spectrum of the composites. Therefore, fresh samples were analysed again with minimal laser exposure, while limiting the spectral range to below $1000 \mathrm{~cm}^{-1}$. As can be seen from Fig. 2(d), the spectrum of the pure- $\mathrm{MoO}_{2}$ sample does not show any variation from the previous scan. In contrast, the spectra of the composite samples show peaks that do not match those of the pure- $\mathrm{MoO}_{2}$. This is due to the nanosize nature of the $\mathrm{MoO}_{2}$ particles in the hybrid samples, which are more susceptible to oxidation by laser irradiation than larger particles. This phenomenon has been reported by Camacho-Lopez et al., and it is associated with oxidation of $\mathrm{MoO}_{2}$ to $\mathrm{MoO}_{x}$ by laser irradiation. ${ }^{52}$

The surface morphology of the samples was characterised using SEM, and the micrographs are presented in Fig. 3. Sample GM31 (Fig. 3(a)) shows a similar structure to the corrugated pure-graphene sample (Fig. S1(c)†), while sample GM13 (Fig. 3(g)) shows a particle like structure similar to that of the pure- $\mathrm{MoO}_{2}$ (Fig. S1(a)†). A combination of corrugated sheets and agglomerated particles can be observed on the surface of GM11 (Fig. 3(d)). TEM was used to further study the morphology of the samples. The graphene sheets of sample GM31 (Fig. 3(b)) appear smooth. Energy dispersive X-ray spectroscopy (EDS) was performed on the GM31 sheets to map the molybdenum element, and the results are presented in Fig. S2.† Elemental mapping of the sheets shows the element Mo distributed across all the areas of the sheets. Using high resolution TEM (HRTEM), the $\mathrm{MoO}_{2}$ nanoparticles were resolved, and an image is presented in Fig. 3(c). The particle size is about 2 $\pm 0.5 \mathrm{~nm}$ (from 50 different particles in 3 different areas), and the lattice spacing was measured to be $0.24 \mathrm{~nm}$, corresponding to the $d$-spacing of the ( $(\overline{2} 11)$ plane. Graphene sheets of a few layer in thickness can also be seen from the HRTEM image, and the $d$ spacing $(0.36 \mathrm{~nm})$ of the $(002)$ plane of the graphene is also marked. A TEM micrograph of GM11 is shown in Fig. 3(e), where the graphene sheets are densely populated by $\mathrm{MoO}_{2}$ nanoparticles. A selected area electron diffraction (SAED) image is also presented in the inset of Fig. 3(e), and the diffuse rings can 


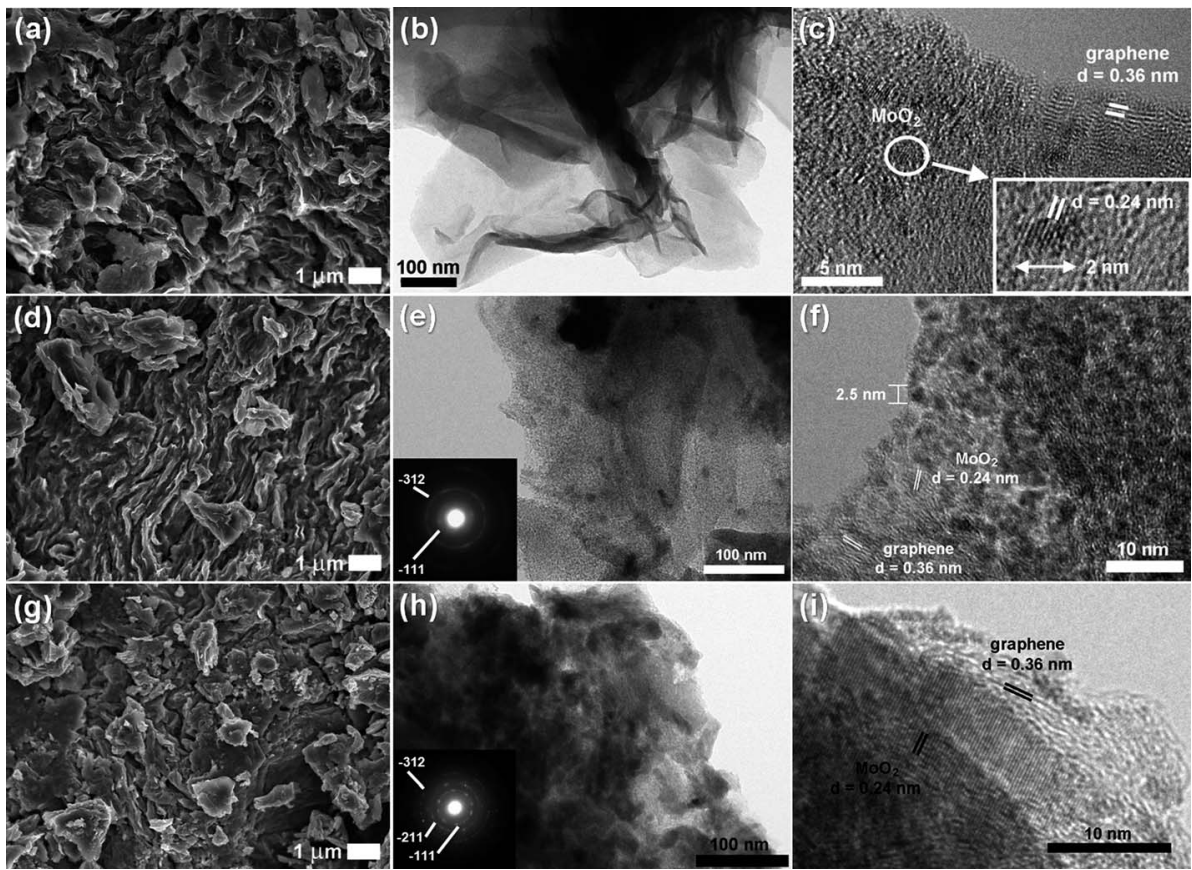

Fig. 3 Scanning electron micrographs of (a) GM31, (d) GM11, and (g) GM13. Transmission electron micrographs of (b and c) GM31, (e and f) GM11, and (h and i) GM13. The inset of (c) is the enlarged image of the area indicated by the white ring; insets of (e) and (h) are the corresponding electron diffraction patterns.

be indexed to the (111) and ( $\overline{3} 12)$ planes. When investigated under HRTEM, the nanoparticles $(2.5 \pm 0.5 \mathrm{~nm})$ can be seen to be covering the surfaces of the graphene sheets. The lattice spacing of the particles and of the sheets can be related to the $d$ spacing of the (211) plane of $\mathrm{MoO}_{2}$ and the (002) plane of graphene, respectively, as indicated in Fig. 3(f). Both sample GM31 and sample GM11 show a 2-dimensional morphology of graphene sheets, with $\mathrm{MoO}_{2}$ nanoparticles anchored on the surface. There could be two explanations to the driving force for anchoring $\mathrm{MoO}_{2}$ particles onto graphene sheets. The first is the electrostatic attraction between the oxygen functional group and the molybdenum ions. There are other reports on metal oxide nanoparticles anchored on graphene sheets and the electrostatic attraction was believed to be the main driving force. ${ }^{23,24,31}$ Secondly, phosphomolybdic acid is known to spontaneously form a thin layer on carbon, pyrolytic graphite and carbon nanotubes. ${ }^{53-55}$ The proximity of the precursors will encourage anchoring of $\mathrm{MoO}_{2}$ particles on graphene sheets after thermal reduction. On the other hand, sample GM13 (Fig. 3(h)) shows large agglomerated particles with graphene sheets. Unlike the 2dimensional morphology of GM11 and GM31, GM13 is highly aggregated and forms large clusters with the graphene sheets. We could not determine the average particle size due to the aggregation. The corresponding SAED pattern of the image is shown in the inset of Fig. 1(h), where the rings can be indexed to the monoclinic $\mathrm{MoO}_{2}$ phase, which is consistent with the XRD results. The sample was then investigated at higher magnification, and the micrograph is presented in Fig. 3(i). A large crystal of $\mathrm{MoO}_{2}(>30 \mathrm{~nm})$ can be seen in the image, and the lattice spacing was measured as $0.24 \mathrm{~nm}$, which corresponds to the ( $(\overline{2} 11)$ plane of $\mathrm{MoO}_{2}$. Graphene sheets and smaller particles of $\mathrm{MoO}_{2}$ $(3 \mathrm{~nm})$ can also be seen in the micrograph.
Lithium storage properties of the graphene- $\mathrm{MoO}_{2}$ composites were investigated using the galvanostatic charge-discharge method. The charging capacity of the samples at $200 \mathrm{~mA} \mathrm{~g}^{-1}$ over 50 cycles is plotted in Fig. 4(a). Among the composite samples, GM13 exhibited the highest capacity of $640 \mathrm{~mA} \mathrm{~h} \mathrm{~g}^{-1}$, while GM31 exhibited the lowest capacity of $380 \mathrm{~mA} \mathrm{~h} \mathrm{~g}^{-1}$, with GM11 retaining $510 \mathrm{~mA} \mathrm{~h} \mathrm{~g}^{-1}$ after 50 cycles. The differences in capacity are mainly due to the content of $\mathrm{MoO}_{2}$ in the samples. This is because the capacity of pure- $\mathrm{MoO}_{2}$ is higher than that of puregraphene. All three composite samples show better cycling stability compared to the pure- $\mathrm{MoO}_{2}$ sample, and this can be attributed to the buffering effect of the graphene sheets, which prevents any serious pulverisation of $\mathrm{MoO}_{2}$. In addition, the interesting feature of capacity increase can be observed for the sample GM13 and the pure- $\mathrm{MoO}_{2}$ in the initial cycles. This phenomenon can be related to the electrochemical milling effect which occurs during lithium reactions with transition metal oxides. It can also be seen as an activation process, where more active sites inside the particles can be accessed by the lithium ions after the size of individual particles is reduced through electrochemical cycling. Samples GM11 and GM31 do not show any activation trend, due to the smaller particle size $(<3 \mathrm{~nm}$; Fig. 3(c) and (f)). The composite samples were further tested for cycling performance at higher rates, as shown in Fig. 4(b). At $1.0 \mathrm{~A} \mathrm{~g}^{-1}$, sample GM13 showed the highest capacity $\left(480 \mathrm{~mA} \mathrm{~h} \mathrm{~g}^{-1}\right)$ after 100 cycles. Samples GM11 and GM31 retained $340 \mathrm{~mA} \mathrm{~h} \mathrm{~g}^{-1}$ and $270 \mathrm{~mA} \mathrm{~h} \mathrm{~g}{ }^{-1}$, respectively, under the same conditions. The cycling tests at $1.0 \mathrm{~A} \mathrm{~g}^{-1}$ also show the same trend as the tests at $0.2 \mathrm{~A} \mathrm{~g} \mathrm{~g}^{-1}$, and this confirms that the capacity of the material depends mainly on the composition.

The voltage profiles of all the samples tested at low rates are presented in Fig. $\mathrm{S} 3, \dagger$ and the insets of the figures are the 

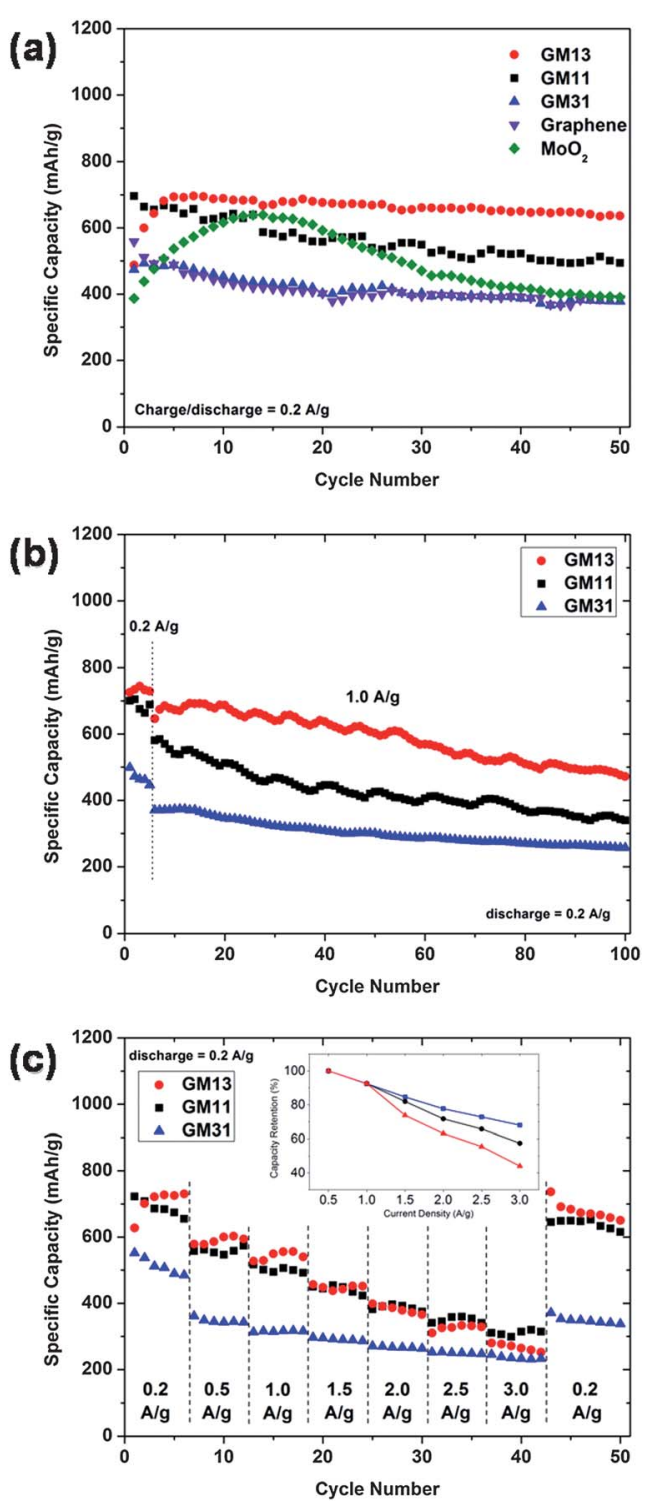

Fig. 4 (a) Cycling performance of the graphene- $\mathrm{MoO}_{2}$ samples at $0.2 \mathrm{~A}$ $\mathrm{g}^{-1}$; (b) cycling performance of the samples at $1.0 \mathrm{~A} \mathrm{~g} \mathrm{~g}^{-1}$; and (c) rate capability of the samples up to $3.0 \mathrm{~A} \mathrm{~g}^{-1}$; the inset of (c) is the capacity retention of the samples at varying current densities.

coulombic efficiencies over 50 cycles. Pure- $\mathrm{MoO}_{2}$ shows the highest first cycle efficiency $(76 \%)$, where the irreversible reactions are mainly due to the formation of the solid electrolyte interphase (SEI) layer. On the other hand, pure-graphene shows the lowest coulombic efficiency $(58 \%)$ in the first cycle due to the SEI formation and other irreversible lithium reactions with defects and nanopores in the corrugated structure. ${ }^{7}$ As expected, the initial coulombic efficiencies of the composite samples are between those of the pure-graphene and the pure- $\mathrm{MoO}_{2}$ samples. The efficiencies recorded for GM13, GM11, and GM31 are 75\%, $68 \%$, and $60 \%$, respectively.

The lithium reaction mechanism can be interpreted from the voltage profiles of each sample. However, for better understanding of the electrochemical reactions, cyclic voltammetry of the samples was conducted at a slow scan rate of $0.1 \mathrm{mV} \mathrm{s}^{-1}$, and the voltammograms are presented in Fig. S4. $\dagger$ The lithium reaction of the pure- $\mathrm{MoO}_{2}$ sample can be observed from Fig. S4(e). $\dagger$ At the first discharge, several broad humps appear from $1.5 \mathrm{~V}$ to $0.01 \mathrm{~V}$, which can be attributed to the lithium reaction with $\mathrm{MoO}_{2}$ and the formation of the SEI. From the second cycle, two distinct redox couples at $1.25 \mathrm{~V} / 1.5 \mathrm{~V}$ and $1.5 \mathrm{~V} / 1.75 \mathrm{~V}$ can be observed, which are highly reversible. They can be attributed to the lithium reaction with $\mathrm{MoO}_{2}$, which is accompanied by the monoclinic-orthorhombic-monoclinic phase transition. ${ }^{32,46}$ For all three composite samples, a broad hump centred around $1.5 \mathrm{~V}$ during charging, which may correspond to the lithium reaction with $\mathrm{MoO}_{2}$, and a sharp peak indicating lithium intercalation into graphene in the low voltage region during discharging were observed from the $\mathrm{CV}$ profiles. These results are consistent with the voltage profiles (Fig. S3†), as no obvious plateaus are observed for the composite samples. One of the possibilities that may contribute to the absence of sharp redox peaks corresponding to lithium reactions with $\mathrm{MoO}_{2}$ is the smaller particle size and the low crystallinity, as indicated from the TEM analysis. Furthermore, the CV of the pure- $\mathrm{MoO}_{2}$ at the $50^{\text {th }}$ cycle shows a similar profile to those of the composite samples. The reduction in particle size and crystallinity may be due to the effects of electrochemical milling, which has been previously studied. Furthermore, the three composite samples were tested for rate capabilities, as shown in Fig. 4(c), and the capacity retention plot is shown in the inset. At the lower rates of $0.5 \mathrm{~A} \mathrm{~g}^{-1}$ and $1.0 \mathrm{~A} \mathrm{~g}^{-1}$, sample GM13 exhibited the highest specific capacity, while at $1.5 \mathrm{~A} \mathrm{~g}^{-1}, 2.0 \mathrm{~A} \mathrm{~g}^{-1}, 2.5 \mathrm{~A} \mathrm{~g}^{-1}$, and $3.0 \mathrm{~A} \mathrm{~g}^{-1}$, sample GM11 exhibited the highest specific capacity. As for the capacity retention, both GM13 and GM11 showed the same percentage for $1.0 \mathrm{~A} \mathrm{~g}^{-1}$. At higher rates, GM11 had higher capacity retention compared to GM13. This phenomenon is most likely due to the higher graphene content in GM11, which contributes to more efficient electron transfer to the active material. In addition, the smaller $\mathrm{MoO}_{2}$ particle size also reduces the lithium-ion pathways into the material. The same pattern can also be observed when comparing GM11 and GM31 from $0.5 \mathrm{~A}$ $\mathrm{g}^{-1}$ to $3.0 \mathrm{~A} \mathrm{~g} \mathrm{~g}^{-1}$, where sample GM31 has superior capacity retention. In addition, all three samples showed good capacity recovery when the rate was lowered to $0.2 \mathrm{~A} \mathrm{~g} \mathrm{~g}^{-1}$. Based on the experimental results, we found that the amount of graphene present in each composite sample plays a crucial role in determining the electrochemical performance and morphology of the sample. With a lower graphene ratio (GM13), the nanoparticles in the composite are larger and aggregated. The capacity is the highest, however, when the sample is cycled at low rates due to the higher contribution from $\mathrm{MoO}_{2}$. For the samples with a higher ratio of graphene in the composite, the $\mathrm{MoO}_{2}$ particles became smaller $(<3 \mathrm{~nm})$ and were found to be anchored on the surface of the graphene sheets. Due to the smaller particle size, better distribution, and higher content of graphene, the rate performances of GM11 and GM31 are superior when compared to GM13. Nevertheless, sample GM13 is a more suitable composite for use as a Li-ion battery anode material due to its higher capacity. Although the capacity retention is the poorest, the capacity at $2.0 \mathrm{~A} \mathrm{~g}^{-1}\left(380 \mathrm{~mA} \mathrm{~h} \mathrm{~g}^{-1}\right)$ is still comparable to that of GM11, which is consistent with previously reported work on $\mathrm{MoO}_{2}$-carbon systems, ${ }^{39-46}$ and the theoretical capacity of graphite, which is the current anode material used in commercial Li-ion cells. 


\section{Conclusions}

In summary, we have prepared several graphene- $\mathrm{MoO}_{2}$ composites through a facile synthesis method. When the graphene ratio in the material was higher, the samples showed 2dimensional graphene sheets with $\mathrm{MoO}_{2}$ nanoparticles less than $3 \mathrm{~nm}$ in size anchored to them. When the ratio of graphene was lower, the sample showed an aggregated morphology. Investigation of the electrochemical performance of the graphene$\mathrm{MoO}_{2}$ composites reveals that the sample with the highest $\mathrm{MoO}_{2}$ ratio (GM13) has higher specific capacity and good cycling performance at low rates. Although the capacity retention of GM13 is poorer compared to the other composite samples, the specific capacity at $2.0 \mathrm{~A} \mathrm{~g}^{-1}\left(380 \mathrm{~mA} \mathrm{~h} \mathrm{~g}^{-1}\right)$ is comparable to that of the commercial graphite anode material.

\section{Acknowledgements}

This work was funded by an Australian Research Council (ARC) Discovery Project (DP1094261). The authors would like to thank Dr Tania Silver at the University of Wollongong for critical reading of the manuscript. In addition, the authors acknowledge use of facilities within the UOW Electron Microscopy Centre.

\section{Notes and references}

1 B. Dunn, H. Kamath and J. M. Tarascon, Science, 2011, 334, 928935.

2 Z. Yang, J. Zhang, M. C. W. Kintner-Meyer, X. Lu, D. Choi, J. P. Lemmon and J. Liu, Chem. Rev., 2011, 111, 3577-3613.

3 M. Armand and J. M. Tarascon, Nature, 2008, 451, 652-657.

4 E. Yoo, J. Kim, E. Hosono, H.-s. Zhou, T. Kudo and I. Honma, Nano Lett., 2008, 8, 2277-2282.

5 P. Guo, H. Song and X. Chen, Electrochem. Commun., 2009, 11, 1320-1324.

6 C. Wang, D. Li, C. O. Too and G. G. Wallace, Chem. Mater., 2009, 21, 2604-2606.

7 G. Wang, X. Shen, J. Yao and J. Park, Carbon, 2009, 47, 2049-2053.

8 C.-M. Park, J.-H. Kim, H. Kim and H.-J. Sohn, Chem. Soc. Rev., 2010, 39, 3115 .

9 Z. P. Guo, E. Milin, J. Z. Wang, J. Chen and H. K. Liu, J. Electrochem. Soc., 2005, 152, A2211-A2216.

10 H. K. Liu, Z. P. Guo, J. Z. Wang and K. Konstantinov, J. Mater. Chem., 2010, 20, 10055-10057.

11 Z. P. Guo, Z. W. Zhao, H. K. Liu and S. X. Dou, Carbon, 2005, 43, 1392-1399.

12 D. Deng, M. G. Kim, J. Y. Lee and J. Cho, Energy Environ. Sci., 2009, 2, 818-837.

13 N.-S. Choi, Y. Yao, Y. Cui and J. Cho, J. Mater. Chem., 2011, 21, 9825-9840.

14 M.-H. Park, Y. Cho, K. Kim, J. Kim, M. Liu and J. Cho, Angew. Chem., Int. Ed., 2011, 50, 9647-9650.

15 M. F. Hassan, Z. P. Guo, Z. Chen and H. K. Liu, J. Power Sources, 2010, 195, 2372-2376.

16 P. Balaya, H. Li, L. Kienle and J. Maier, Adv. Funct. Mater., 2003, 13, 621-625.

17 L. Yuan, Z. P. Guo, K. Konstantinov, P. Munroe and H. K. Liu, Electrochem. Solid-State Lett., 2006, 9, A524-A528.

18 P. Zhang, Z. P. Guo and H. K. Liu, Electrochim. Acta, 2010, 55, 85218526.

19 P. Zhang, Z. P. Guo, Y. Huang, D. Jia and H. K. Liu, J. Power Sources, 2011, 196, 6987-6991.

20 A. K. Geim and K. S. Novoselov, Nat. Mater., 2007, 6, 183-191.

21 D. Li and R. B. Kaner, Science, 2008, 320, 1170-1171.
22 D. Li, M. B. Mueller, S. Gilje, R. B. Kaner and G. G. Wallace, Nat. Nanotechnol., 2008, 3, 101-105.

23 K. H. Seng, Z. P. Guo, Z. X. Chen and H. K. Liu, Adv. Sci. Lett., 2011, 4, 18-23.

24 G. Wang, B. Wang, X. Wang, J. Park, S. Dou, H. Ahn and K. Kim, J. Mater. Chem., 2009, 19, 8378-8384.

25 J. K. Lee, K. B. Smith, C. M. Hayner and H. H. Kung, Chem. Commun., 2010, 46, 2025-2027.

26 L. Li, Z. Guo, A. Du and H. Liu, J. Mater. Chem., 2012, 22, 36003605 .

27 C. Zhang, X. Peng, Z. Guo, C. Cai, Z. Chen, D. Wexler, S. Li and H. Liu, Carbon, 2012, 50, 1897-1903.

28 S.-M. Paek, E. Yoo and I. Honma, Nano Lett., 2009, 9, 72-75.

29 D. Wang, D. Choi, J. Li, Z. Yang, Z. Nie, R. Kou, D. Hu, C. Wang, L. V. Saraf, J. Zhang, I. A. Aksay and J. Liu, ACS Nano, 2009, 3, 907914.

30 H. Wang, L.-F. Cui, Y. Yang, H. S. Casalongue, J. T. Robinson, Y. Liang, Y. Cui and H. Dai, J. Am. Chem. Soc., 2010, 132, 1397813980.

31 Z.-S. Wu, W. Ren, L. Wen, L. Gao, J. Zhao, Z. Chen, G. Zhou, F. Li and H.-M. Cheng, ACS Nano, 2010, 4, 3187-3194.

32 J. R. Dahn and W. R. McKinnon, Solid State Ionics, 1987, 23, 1-7.

33 L. C. Yang, Q. S. Gao, Y. Tang, Y. P. Wu and R. Holze, J. Power Sources, 2008, 179, 357-360.

34 L. C. Yang, Q. S. Gao, Y. H. Zhang, Y. Tang and Y. P. Wu, Electrochem. Commun., 2008, 10, 118-122.

35 Y. Shi, B. Guo, S. A. Corr, Q. Shi, Y.-S. Hu, K. R. Heier, L. Chen, R. Seshadri and G. D. Stucky, Nano Lett., 2009, 9, 4215-4220.

36 D. Koziej, M. D. Rossell, B. Ludi, A. Hintennach, P. Novak, J.-D. Grunwaldt and M. Niederberger, Small, 2011, 7, 377387.

37 B. Guo, X. Fang, B. Li, Y. Shi, C. Ouyang, Y.-S. Hu, Z. Wang, G. D. Stucky and L. Chen, Chem. Mater., 2012, 24, 457-463.

38 Y. G. Liang, S. J. Yang, Z. H. Yi, J. T. Sun and Y. H. Zhou, Mater. Chem. Phys., 2005, 93, 395-398.

39 Y. Sun, X. Hu, J. C. Yu, Q. Li, W. Luo, L. Yuan, W. Zhang and Y. Huang, Energy Environ. Sci., 2011, 4, 2870.

40 Q. Cao, L. Yang, X. Lu, J. Mao, Y. Zhang, Y. Wu and Y. I. Tang, J. Mater. Chem., 2010, 20, 2807-2812.

41 Z. Wang, J. S. Chen, T. Zhu, S. Madhavi and X. W. Lou, Chem. Commun., 2010, 46, 6906-6908.

42 W. Luo, X. Hu, Y. Sun and Y. Huang, Phys. Chem. Chem. Phys., 2011, 13, 16735-16740.

43 L. Zhou, H. B. Wu, Z. Wang and X. W. Lou, ACS Appl. Mater. Interfaces, 2011, 3, 4853-4857.

44 Y. Sun, X. Hu, W. Luo and Y. Huang, J. Mater. Chem., 2012, 22, 425.

45 Y. Xu, R. Yi, B. Yuan, X. Wu, M. Dunwell, Q. Lin, L. Fei, S. Deng, P. Andersen, D. Wang and H. Luo, J. Phys. Chem. Lett., 2012, 3, 309314.

46 Y. Sun, X. Hu, W. Luo and Y. Huang, ACS Nano, 2011, 5, 71007107.

47 G. Du, K. H. Seng, Z. Guo, J. Liu, W. Li, D. Jia, C. Cook, Z. Liu and H. Liu, RSC Adv., 2011, 1, 690-697.

48 F. Pico, E. Morales, J. A. Fernandez, T. A. Centeno, J. Ibanez, R. M. Rojas, J. M. Amarilla and J. M. Rojo, Electrochim. Acta, 2009, 54, 2239-2245.

49 J. T. Zhang, J. Z. Ma, J. W. Jiang and X. S. Zhao, J. Mater. Res., 2010, 25, 1476-1484.

50 J. T. Zhang, J. W. Jiang and X. S. Zhao, J. Phys. Chem. C, 2011, 115, 6448-6454.

51 M. Dieterle and G. Mestl, Phys. Chem. Chem. Phys., 2002, 4, 822826.

52 M. A. Camacho-Lopez, L. Escobar-Alarcon, M. Picquart, R. Arroyo, G. Cordoba and E. Haro-Poniatowski, Opt. Mater., 2011, 33, 480484.

53 M. H. Ge, B. X. Zhong, W. G. Klemperer and A. A. Gewirth, J. Am. Chem. Soc., 1996, 118, 5812-5813.

54 A. Kuhn and F. C. Anson, Langmuir, 1996, 12, 5481-5488.

55 Z. P. Guo, D. M. Han, D. Wexler, R. Zeng and H. K. Liu, Electrochim. Acta, 2008, 53, 6410-6416. 